Western University

Scholarship@Western

Spring 2008

\title{
Infertility and Moral Luck: The Politics of Women Blaming Themselves for Infertility
}

Carolyn McLeod

The University of Western Ontario

Julie Ponesse

The University of Western Ontario

Follow this and additional works at: https://ir.lib.uwo.ca/philosophypub

Part of the Bioethics and Medical Ethics Commons, Feminist, Gender, and Sexuality Studies Commons, and the Philosophy Commons

Citation of this paper:

McLeod, Carolyn and Ponesse, Julie, "Infertility and Moral Luck: The Politics of Women Blaming Themselves for Infertility" (2008). Philosophy Publications. 335.

https://ir.lib.uwo.ca/philosophypub/335 


\title{
Infertility and moral luck: The politics of women blaming themselves for infertility Carolyn McLeod and Julie Ponesse ${ }^{1}$
}

\begin{abstract}
Infertility can be an agonizing experience, especially for women. And, much of the agony has to do with luck: with how unlucky one is in being infertile, as well as how much luck is involved in determining whether one can weather the storm of infertility and perhaps have a child in the end. We argue that bad luck associated with being infertile is often bad moral luck for women. The infertile woman often blames herself or is blamed by others for what is happening to her, even when she cannot control or prevent these events. She has simply had bad luck. We focus on the self-blame of infertile women and show how it stems from pro-natalism that targets women. We also argue that for women, regret is overall a better moral response to infertility than self-blame.
\end{abstract}

Many bad reproductive experiences, such as unwanted pregnancy and infertility, are partly or wholly the result of luck. Such luck often has bad moral effects, in that people are blamed for it or more generally, lose moral standing because of it. Moreover, these people are more likely to be women than men: women are more likely to suffer negative moral effects from bad reproductive luck or in other words, to suffer from what we call bad reproductive "moral luck."2 Drawing on psychological literature about infertility, but also on philosophical work on luck, blame, and responsibility, we examine these claims using the test-case of infertility. In so doing, we hope to add important discussion about luck and its moral effects to feminist reproductive ethics, which has hitherto focused almost exclusively on reproductive choice, 
paying little attention to luck. Feminists have rightly lamented the fact that many women have little control over their reproductive lives; but rarely do feminists mention that the accompanying luck for these women is often bad moral luck, which is worse for women than merely lacking control.

One notable exception to the claim that feminists have ignored reproductive moral luck is Donna Dickenson's work on what risks "can women be asked to bear" in reproductive health care, given that the outcomes of risky reproductive decisions can be morally unlucky (2003). But we deal with moral luck more broadly than Dickenson does. For we include moral luck that concerns, not the outcomes of people's risky decisions, but the circumstances that people face more generally. An example of such circumstantial luck is the moral luck that accompanies infertility when the infertility itself is not a product of an agent's choices.

Generally, with this paper, we hope to initiate an in-depth conversation about the moral effects of reproductive luck on women. More specifically, we want to persuade readers of the fact that women often morally blame themselves for infertility, even though they are rarely a morally relevant cause of the infertility, and moreover, that their self-blame is intimately tied to their oppression as women. When discussing how women blame themselves for infertility, we also refer to how other people blame them. Blame for infertility is an extreme example of reproductive moral luck ${ }^{3}$; and to some people, it will seem farfetched that educated women, in particular, experience such blame. We focus on blame for infertility because it is extreme and it shows how serious the issue of reproductive moral luck is for women.

The structure of the paper is as follows: first, we describe the luck involved in being infertile; second, we explain why many women experience this luck as moral luck (and more specifically, as blame); and third, we assess whether this moral luck is always bad luck and also 
when regret about infertility is bad or good. In general, the point of identifying when luck is both moral and bad is to reveal patterns of blame that are unfair and potentially morally damaging. Our analysis exposes common patterns of this sort that negatively affect the lives of infertile women.

\section{Luck in being infertile}

So much of what happens during the experience of infertility is wholly or partly beyond one's control; that is, it is a matter of luck. One is unlucky in being infertile. ${ }^{4}$ But one is also either unlucky or lucky when it comes to being able to act on a preference for assisted reproduction or adoption, to having a relationship with one's partner that can withstand the pressures of infertility, to having supportive friends and family, and so on. There are general and overlapping forms of luck that occur for infertile people insofar as they are infertile and that are based on biological or social facts about infertility, infertility treatments, and adoption. These forms may or may not appear as luck to the infertile person, who might view them instead as products of her will.

We focus this discussion on the luck that enters into infertility, and especially on what we call "biological luck." Further, we concentrate on the luck of being infertile for women and on cases where this luck is bad. The luck of being infertile is often bad for women, because of the intensity with which women tend to want to bear children or feel the need to do so (for reasons that can include avoiding social ostracism or even death). Of course, some women do not have this desire (i.e., to bear children or bear more children). We accept, given such cases, that the luck of being infertile may not be bad for women and in fact, can be good, for it can protect 
women from unwanted pregnancies. Nonetheless, we assume that such luck for women is usually bad.

Some of the luck associated with infertility is intimately connected to one's biology and more specifically, to aspects of it that one can do little to nothing about. The most obvious instance of such biological luck is the luck involved in simply being infertile. (A further instance is the bad luck of experiencing serious side effects from infertility treatments, that is, if one pursues such treatments. ${ }^{6}$ ) Although one can be infertile because of luck that is not purely biological—we give examples later-the luck involved in being infertile will always be partly biological. $^{7}$

People often fail to recognize how much being infertile is biological luck. They adhere to the pervasive belief that stress causes infertility (Weschler 2002) and that if a woman simply relaxes or stops worrying about getting pregnant, then she will get pregnant. "Go on vacation," "stop working so hard," "adopt a baby": each of these is supposed to cure infertility. But in reality, stress may not be a cause of infertility; the data on whether it is a cause are inconclusive (Homan et al. 2007). Also, there are common causes of infertility that have nothing to do with stress or with obsessing over pregnancy. Examples include endometriosis, certain chromosomal abnormalities, and congenital anomalies of the cervix and uterus (Kelly-Weeder and O'Connor 2006). These are physical causes of infertility for which the infertile person cannot be responsible.

Infertility also can result from behavioral causes or lifestyle factors. People with the relevant lifestyle factors could be partially responsible for infertility that results from them, but they could not be fully responsible for it (i.e., in the sense of having caused the infertility), because these lifestyle factors only make infertility more likely to occur, rather than rendering it 
inevitable. How a lifestyle factor interacts with one's biology matters, which means that any resulting infertility will be a matter of biological luck to some degree. Lifestyle factors for infertility include delayed childbearing, smoking, extremes of weight, and sexual behavior that puts one at risk for certain infections, such as a chlamydial infection (Kelly-Weeder and O'Connor 2006; Homan et al. 2007).

We assume that women whose infertility is connected with a lifestyle factor are rarely, if ever, responsible in a moral sense for their infertility. To be responsible in this sense, they would have to have chosen the relevant lifestyle, and moreover, it would have to be reasonable to assume that they appreciated (or at least should have appreciated) the risk of infertility from this lifestyle. In their use of the term "lifestyle factors," medical researchers imply that the relevant factors stem from people's choices, rather than from luck, which is not necessarily the case. Researchers define lifestyle factors as "behaviours and circumstances that are, or were once, modifiable and can be a contributing factor to [in]fertility" (Homan et al. 2007). But lifestyle factors that are modifiable, yet only theoretically (not realistically) produce only bad luck (Homan et al. 2007, 12). For example, assuming that psychological stress is a lifestyle factor for infertility, stress is not something that all people realistically can modify, because some people live in circumstances that are both profoundly stressful and unavoidable. Also, lifestyle factors that were once modifiable, yet were not modified because the person did not know that the behaviors were risk factors for infertility, will simply create bad luck for her, that is, if she becomes infertile partly as a result of these behaviors. She is not morally responsible if she could not have known that her behavior might affect her fertility. We assume that most women are in a state of ignorance when they behave in ways that might compromise their fertility, because most women would not intentionally compromise their fertility. 
Perhaps, however, a woman would be morally responsible for lifestyle-related infertility if she simply should have known how to modify her behavior to decrease her risk of becoming infertile. In short, she simply should have known better. And if that is true, then her infertility would not be just a matter of luck. We usually say that people "should have known better" when they fail to know what is deemed to be common knowledge. (For example, it is common knowledge that leaving young children unattended near water is dangerous; someone who does so should have known better, even if she did not actually know better.) So the question of whether people with lifestyle-related infertility should have known better essentially comes down to whether the lifestyle factors for infertility are common knowledge. We cannot prove that they are not common knowledge everywhere (such a task we leave to feminist sociologists who are interested in women's reproductive moral luck), but we can say this: given how many myths and rumors often surround infertility and the lifestyles that purportedly cause it (Weschler 2002, Kaler 2007), ${ }^{8}$ and also given uncertainty within science about what are the true lifestyle factors for infertility (e.g., uncertainty now about whether stress and caffeine consumption are such factors: Homan et al. 2007), we sincerely doubt that these factors are or even could be widely known. Before doing research for this essay, neither of us even understood what most scientists now consider to be the lifestyle factors for infertility, though we study reproductive ethics! One exception was our understanding that delayed childbearing can cause infertility. But anecdotal evidence of pregnancies among 40- to 45 -year old women leads us to wonder how much of a delay is problematic. Moreover, we question whether delayed childbearing is even a choice for many women, given that the delay is often financially or professionally necessary. In summary then, we are skeptical that women who are infertile because of lifestyle factors can be held morally responsible for their infertility. 
This discussion of lifestyle factors for infertility reveals that forms of luck other than biological ones can contribute to one's infertility. The bad luck of being infertile because of a certain lifestyle will be not only bad biological luck, but also bad luck in being either stuck with certain lifestyles (unchosen ones) or embedded in societies that do not properly educate people about potential causes of infertility.

The bad luck that goes into being infertile is part of the lived experience of infertility for many people. Consider that anger is a common response to infertility (Greil 1997, 1682; Sherrod 2004, 44), and it is not unreasonable to assume that the anger comes from a sense of unfairness: that one is infertile when so many other people—some of whom have "risky" lifestyles—can conceive when they want, or worse, by accident!

Biological luck, along with other forms of luck, is therefore a key aspect of infertility. And as we will see, such luck, insofar as it results in infertility, can be moral, especially for women. Of course, we do not believe that infertility is the only biological condition where the luck of having the condition can be moral luck to some degree, either because people are blamed for the condition or are treated as though they were morally inferior because of it. (Any stigmatized condition would fit this description.) Infertility is one example, though a specifically feminist example, of bad biological luck that often manifests itself as moral luck.

\section{Moral luck in being infertile: Women blaming themselves}

We have claimed that the bad biological luck of being infertile is often moral luck for women because they take, or are given, moral responsibility for the infertility. They engage in self-blame and experience 'other-blame' (blame by others) insofar as they are infertile women. 
Our argument, which focuses predominantly on self-blame, requires that we clarify the meanings of certain moral terms, namely moral luck, responsibility, and blame.

According to Thomas Nagel, "[w]here a significant aspect of what someone does depends on factors beyond his control, yet we continue to treat him in that respect as an object of moral judgment, it can be called moral luck" $(1993,59)$. In other words, moral luck occurs whenever luck "makes a moral difference": that is, to the moral evaluation of a person's actions or to her status as a good or bad person (Latus 2005). This explanation does not specify to whom the luck does or ought to make a moral difference. We assume that moral luck could make a moral difference only to people of a certain social group or culture, because of how these people have been socialized to think about morality (or about women or fertility). For instance, the luck of being infertile makes a moral difference for many women because of the pro-natalism they face, as we will discuss. But the luck may not make a moral difference for everyone around these women, some of whom (hopefully) will not blame them for the infertility. Still, we call this luck "moral luck." It does make a moral difference, if only from some perspectives and for some people. ${ }^{9}$

We use the term "responsibility" in different senses and the term "blame" in a particular sense. In particular, we distinguish between causal and moral responsibility. People can be causally responsible for certain outcomes without being morally responsible for anything. They are causally responsible if through their own actions (versus through some involuntary bodily movement or process), they brought about the relevant outcomes (Mackenzie 1992, 138). But they are not morally responsible if there is nothing that is morally salient about these outcomes (e.g., about a door being opened without anyone being harmed as a result) or about their intentions. Alternatively, even if the outcomes are morally salient (e.g., because someone was 
harmed), those who caused them still might not be morally responsible for them, because they may not have known, and were not in a position to have known, about the potential harm. Unlike causal responsibility, moral responsibility requires that people's actions have a moral dimension to them and that they were aware or should have been aware of this dimension when performing the action.

In addition, we briefly mention different senses of moral responsibility, including what Claudia Card calls the "credit sense of responsibility—owning up to having been the (morally) relevant cause of something's happening or not happening, taking the credit (blame) for it" and what she labels the "administrative or managerial sense of responsibility — undertaking to size up and organize possibilities comprehensively, deciding which should be realized and how" (1996, 28). The first sense of responsibility, the credit sense, is "backward-looking": it looks back to who was the cause of something's happening and who was to blame for it. By contrast, the second sense is "forward-looking": it looks forward to who will manage a situation that needs managing. Each of the above forms of responsibility—causal responsibility, moral responsibility in the credit sense, and moral responsibility in the managerial sense-figure in our discussion of the moral luck that women face because of being infertile.

The blame associated with the credit sense of responsibility is moral blame, which is also the kind of blame we focus on. Blame may not always be moral in kind; for example, I might blame myself for forgetting to put a carton of milk back in the refrigerator if the milk goes bad, but I do not experience this blame as a moral reprimand. Blame of a moral kind usually prompts negative moral feelings, such as guilt, shame, or feeling that one has let people down. By contrast, blame for letting the milk go bad would normally only generate disappointment or 
perhaps frustration, neither of which are necessarily moral feelings. In referring to blame below (e.g., to whether women genuinely blame themselves for infertility), we mean moral blame.

Women could take responsibility for their infertility in any of the above senses: they could simply assume that they are causally responsible for it, they could blame themselves for it, or they could take responsibility for managing it. Often women, as opposed to men, take responsibility in the managerial sense for infertility. For example, they are more likely than men to "seek out information about infertility" and to "initiate treatment" for it (Greil 1997). What explains why many women become managers of infertility is probably their desire to have children, which tends to be stronger than men's, and the influence of a sexist and pro-natalist culture that as much delivers the message that women are responsible for overcoming infertility as it does that women are to blame for it. Notice that women can assume managerial responsibility for infertility without taking causal or credit responsibility for it (just as anyone can work to solve a problem that s/he did not cause, in a morally relevant sense or not). Heterosexual women probably manage their infertility more than their male partners do even when the women recognize that they are not to blame for the infertility.

Our argument, however, focuses on how, or more importantly whether, women take responsibility for infertility in the credit sense: that is, whether they blame themselves for it. Our aim is to show that self-blame among women for infertility is common, although we discuss reasons why other-blame is common as well. In showing that women blame themselves, we also reveal why they blame themselves, where the "why" is connected with the oppression of women. ${ }^{10}$

It intuitively makes sense to us that many women would blame themselves for infertility and in so doing, point to any number of possible causes for it: not timing intercourse properly, 
being too "stressed out," having a bad diet, having a past abortion, having engaged in risky sexual behavior, and so on. These may not be true causes of a woman's infertility, however, or if they are, the woman may not (and could not easily) have known that they would compromise her fertility, in which case, while she may be causally responsible for the infertility, she could not legitimately be blamed for it. As suggested above, most, if not all, women who blame themselves for infertility are either merely causally responsible for it or are not causally responsible for it at all. The only clear exception would be a woman who autonomously chose to be sterilized, but then changed her mind about wanting to get pregnant. She could rightfully blame herself for being infertile, since she knowingly and freely undermined her chances of getting pregnant. Most women ought not to blame themselves for infertility, however; yet they do it anyway.

But one could legitimately ask, "Do women truly blame themselves for infertility, or do they just say that they are responsible for it, from which it could follow that they are only causally responsible for it?" For three reasons, we think that the women do in fact blame themselves; that something genuinely evaluative is going on.

The first reason is this: other people often blame women for infertility, and self-blame and other-blame tend to go hand in hand. (In other words, women blame themselves because other people blame them.) In some societies, blame by others for infertility, which is both rampant and overt, is directed primarily at women. These societies are ones in which divorce, abandonment, social ostracism, and abuse are highly correlated with infertility for women (Dyer et al. 2005; Guntupalli and Chenchelgudem 2004).$^{11}$ The majority of people—or at least the majority of dominant societal members - must support these practices for them to continue, which means that the majority must blame women for infertility. (Why else would they endorse such mistreatment of women?) Blame by others need not be so overt or severe, however. For 
example, the pervasive belief that stress causes infertility is a source of blame for women that is certainly palpable, but not severe. Telling a woman that she should "just relax" or "should stop working so hard" implies that the problem is hers to begin with. Such advice, which can be wellmeaning, has negative implications for its receiver. The message is essentially one of blame: "if you relaxed more and were not so preoccupied with other things, then you would be pregnant. Moreover, relaxing more and working less are surely within your control.” Such other-blame easily can be converted to self-blame.

A second reason for thinking that women who say, "I'm responsible for the infertility," genuinely blame themselves for it is that the thought coheres with psychological studies about women who are infertile. In fact, studies dealing with self-blame overwhelmingly conclude that women who experience infertility blame themselves for it: they do so more often than men and even when the cause of the infertility is unknown (Greil 1997; Schneider and Forthofer 2005; Peterson et al. 2006). ${ }^{12}$ They also blame themselves more, in comparison with other women, if their culture is especially pro-natalist toward women (van Rooij et al. 2007). This research, although important to our project, is problematic because it often fails to distinguish carefully between blameworthiness and causal responsibility. ${ }^{13}$ Women say that they are responsible for the infertility, and researchers assume that they therefore blame themselves, when in fact, they could merely be accepting that they caused the infertility (blamelessly). So the research does not obviously corroborate our thesis about self-blame. But if we explore the research findings in more detail, we will see that the best interpretation of them does support our thesis.

Consider first the finding that women whose culture is especially pro-natalist blame themselves for infertility more than other women. This result suggests that pro-natalism has something to do with the "self-blame." According to pro-natalist norms, childbearing is a 
woman's social role and if a woman does not bear children, then she does not "count" (i.e., have value) in society, or she counts less than other women. If an infertile woman or people around her believe that childbearing is her social role, then she's likely genuinely to blame herself or be blamed for the infertility. Consider that with social roles come social responsibilities and that the relevant responsibility here is to bear children: for one's own sake, for that of one's spouse, for one's parents, for one's spouse's parents, or for one's existing children. If women have internalized such pro-natalism — which they can do without endorsing it (Calhoun 1995) — then in all likelihood, they will feel that they have let people down if they cannot get pregnant; for that is how people commonly feel when they cannot fulfill their social role, for whatever reason. Believing that one has let people down indicates that one blames one's self.

Consider second the finding that women who experience unexplained infertility tend to assume that they are the cause of the infertility and take responsibility for it. Now, why would women do that? We think the answer is similar to the answer to why self-blame is greatest among women who face severe pro-natalism: to some degree, the women have internalized the view that their social role as women is to reproduce. And if that is their role, then as women, they should be able to reproduce. ${ }^{14}$ If they cannot do it, then there must be something wrong with them. Furthermore, if they cannot do it, then they let other people down. Thus, they attribute the cause of the unexplained infertility to themselves and also blame themselves for it.

The previous explanation is our preferred explanation for why women take responsibility for unexplained infertility; and the explanation suggests that the responsibility they take is moral, not causal. There is at least one other possible explanation, however, that we ought to consider, one which suggests that the relevant responsibility is causal and therefore, that women do not truly blame themselves when the cause of infertility is unknown. 
Women might take responsibility for unexplained infertility— publicly, if not privately— because they want to protect their male partners from the shame or embarrassment of thinking that they themselves are infertile. And if that is their purpose, then they need not take moral responsibility for the infertility, because assuming causal responsibility is enough to save their partners' male egos. Unfortunately, this explanation does not jive with recent research on selfblame among infertile women in the West (Peronace et al. 2007). This literature reveals that these women, in general, will not publicly accept blame for male-factor infertility, though one would assume that they would if they were concerned about protecting their partner from embarrassment. Therefore, they probably would not take responsibility for unexplained infertility either. This same literature also concludes that men tend not to find male-factor infertility to be particularly distressing, compared to female-factor or unexplained infertility. ${ }^{15}$ Women who are partnered with these men may be well aware that virility is not a major source of self-esteem for them. If so, then these women would not assume that by attributing the cause of unexplained infertility to themselves, they would saving their partners from serious psychic injury. Of course, some women might assume as much, and for good reason, because they inhabit cultures in which virility is clearly important for men. Where it is important, the previous explanation for selfattribution among women for the causes of infertility is certainly plausible.

But we think that our explanation - that women attribute the cause of unexplained infertility to themselves because of pro-natalist social norms that encourage women to blame themselves rather than just take causal responsibility—coheres best with all of the empirical literature and arguably with different cultural backgrounds of infertile women and men, including backgrounds that are not especially pro-natalist. Even in societies where women who 
do not reproduce or bear children also have value, cultural messages marking reproduction as the domain of women are strong.

There is one final reason why we think it is false to assume that when women say they are responsible for their infertility, they mean causally responsible. When people believe themselves responsible for a dire outcome, it is unusual for them just to accept causal responsibility for it. They blame themselves. For example, if I make what turns out to be a poor financial decision, one that puts me in financial ruin, then I will probably blame myself for making a poor decision, even if I could not have known that it would turn out to be poor (or that I would). The alternative of believing that horrible events, such as financial ruin, occur by chance alone - that I have no control over whether they do occur - is too hard to accept. Hence, I blame myself and assume that things turned out badly because I failed to exert the control I do have over whether things go well or badly. Similarly with infertility: thinking that the world is just unfair or that their bodies have betrayed them may not be an option, especially for women who find infertility to be devastating and who want to believe that they can overcome it by making different choices than ones they made in the past. Here, self-blame is a coping mechanism for women, especially perhaps for those who have internalized the pro-natalist message that infertility is a disaster for women.

If persuasive, the previous discussion shows that the responsibility many women attribute to themselves for infertility is responsibility in the credit sense- "taking the credit (blame) for it" (Card 1996, 28) — rather than the causal sense. And therefore, bad biological luck of being infertile for these women is moral luck. (It would be mere luck if the responsibility they took were causal, and thus, non-moral.) To be clear, the idea is not that infertile men never face moral 
luck of this sort, but that whatever amount of it they do experience is significantly less than what women experience.

\section{Analyzing self-blame and regret for infertility}

There is some question as to whether the self-blame of many infertile women could be helpful to them, rather than harmful, especially when it serves as a coping mechanism. If it is helpful, then the moral luck it represents could be good luck, not bad. We would like to pursue this question and also consider whether regret, instead of blame, would be an appropriate response by many women to infertility, whether they caused the infertility or not.

One might think that the self-blame of infertile women would be helpful to them because, as explained previously, it can allow them to believe that through their own actions, they can overcome their infertility. It could give them hope, in other words, that future strategies they use to get pregnant will work. In blaming themselves, women assume there was something they could have done to prevent their infertility. Women who assume the opposite- there was nothing they could have done - could find it harder to believe that their future choices will have any effect on whether they get pregnant.

But the previous analysis of the benefits of self-blame is weak for at least three reasons: (1) Obviously, hope that one's attempts at getting pregnant will succeed can be false hope, which itself can be damaging. A woman who continues to believe that her infertility can be resolved by her own management may be unrealistically optimistic about, and therefore more likely to be devastated by, bad outcomes. (2) The psychological literature reveals overall that self-blame is not a good coping strategy for infertile women - the distress they experience as a result of the infertility is usually higher if they blame themselves for being infertile than if they do not (see, 
e.g., Peterson et al. 2006). (3) The blame can reinforce the pro-natalist and sexist norm that women ought to feel badly about themselves if they cannot get pregnant. In particular, blame will have this effect if it stems from pro-natalist and sexist social forces, as much of women's self-blame does, according to the previous section of this paper. For example, self-blame that exists because of other-blame that targets women in general rather than men is clearly linked with these forces, as is the self-blame that women feel because of unexplained infertility. Selfblame that has it roots in pro-natalism and sexism cannot be good for women.

For these reasons, we maintain that the reproductive moral luck of self-blame is generally bad for infertile women. In general, these women should not engage in self-blame or be encouraged to do so. There may be some women who legitimately could blame themselves for infertility - as noted previously, with the example of the woman who autonomously chose to be sterilized—but again, we assume that such cases are few and far between.

Although self-blame by women is normally an inappropriate response to the bad luck of being infertile, one might wonder whether regret is ever an appropriate response, and if so, under what conditions. Women who don't blame themselves for infertility almost certainly will regret it, that is, if they want to get pregnant. But whether regret is appropriate can depend on exactly what the woman is regretting. We consider different possibilities below and do so under the general headings of: regret for past actions (that may have caused one's infertility), regret for one's circumstances (that exist because of the infertility), and regret for one's constitution (as an infertile woman).

First, a woman might regret past actions that she assumes contributed to her infertility and regret them without believing that she was a morally relevant cause of the infertility. For example, a woman can regret having engaged in risky sexual behavior, even if she knows that at 
the time, she did not appreciate the risks and could not have reasonably been expected to do so. Regret of this sort can be inappropriate and would be so if it targeted an action that in all likelihood did not cause the infertility, such as a past abortion that involved no complications. But regretting past actions that could very well have contributed to one's infertility can be appropriate.

Aristotle tells us why, in general, one ought to regret actions for which one cannot be blamed but that are normally blameworthy (i.e., because of the nature of the action-for example, to lie - or because of its effects): the regret signals that the action was involuntary (Nicomachean Ethics 1110b18-20). In certain contexts at least, saying "I regret doing X" suggests that I didn't really want to do X or didn't want what it brought about. Instead, I was coerced into doing it or was under some misconception about what its consequences would be. Hence, the action was not fully autonomous (assuming that voluntariness and knowledge about consequences are important for autonomy; see McLeod 2002). What does this reasoning imply for women who regret infertility for which they are causally but not morally responsible? The regret indicates that they are not morally responsible; and hence, the regret is appropriate.

Regret for past actions also can signal that one is unhappy with what one has lost, or caused others to lose, because of these actions. So the regret reveals the level of one's commitment to a certain good or the level of one's caring for others who lose something because of what one did (intentionally or not). Thus, a woman might regret the lifestyle she had that contributed to her infertility because she truly wishes that she could be a biological mother or wishes that she could now do her part in fulfilling the goal of biological parenthood that she shares with her partner. Regret of this sort can be appropriate as long as the woman's wishes are authentic, as opposed to being determined by outside forces, particularly pro-natalist and sexist 
forces. When a woman truly wants to be a biological parent and to give her partner the experience of being such a parent, it makes sense that she would regret the lifestyle she had that helped to make her infertile.

Second, a woman can regret the circumstances in which her infertility has placed her and regret them without thinking that any past actions of hers caused the infertility. For example, she simply regrets not being able to get pregnant or not being able to give her spouse a biological child. Such regret can be appropriate for reasons discussed in the previous paragraph: the regret is a way of showing how much the woman values pregnancy, biological motherhood, or the interests of someone close to her. But again, these values can be infected with pro-natalism or sexism; for example, the woman might desire to be a biological mother because she believes that her value as a person is defined by her reproductive capacity. One can legitimately question whether such a desire is authentic as opposed to being a mere product of oppression, and in turn, whether regret for not being able to fulfill this desire is appropriate. Regret in this instance could signal what is important, not so much to the woman, but to the culture that oppresses her.

Third, an infertile woman might regret her constitution: who she is and who she has become because of being infertile. For example, she regrets that she is filled with angst or selfblame about her infertility, that she feels sorry for herself when so many others suffer from a fate worse than infertility, that she is incredibly envious of women who bear children, or that she feels incomplete as a woman because of pro-natalist attitudes that she holds but does not endorse.

Regretting who one is as an infertile woman can be both appropriate and required even though identity is not entirely within one's control. As suggested previously, an infertile woman may be who she is, and may feel what she feels, because she has internalized oppressive norms. In that case, oppression has caused moral damage to her character (Tessman 2005; Card 1996). ${ }^{16}$ 
Regretting this effect of oppression is appropriate insofar as it encourages one to remake one's self to whatever degree possible. Here, regret has prospective value for an infertile woman because it spurs her on when trying to alleviate damage to herself, caused by the oppression she has faced, and to respond virtuously to the bad moral effects of her infertility. Because of the regret (and other factors to be sure, such as encouragement from others), she may become a better person than she would have been had she not suffered through the infertility. For example, she could become more courageous, more compassionate toward people who experience trials that are similar to infertility, more aware of her personal relationships that are beneficial and those that are harmful, clearer about her desires that are authentic to her, and so on.

This is not to suggest that taking responsibility for reconstituting a self that has been somewhat mangled by oppression is easy. Card explains that, on the contrary, this process is normally quite difficult (1996). It requires severing relations with people close to you who reinforce the oppression, forming more positive relationships, and silencing inauthentic yet deeply entrenched desires. For women who regret who they are as infertile women, developing a self that is virtuous - that can respond with integrity or grace ${ }^{17}$ to the bad luck of being infertile — will be difficult. Nevertheless, they ought to do it, or at least attempt it; and regretting who they are is an important first step towards developing a better character.

In summary, unlike self-blame, regret can be a legitimate moral response to the bad luck of being infertile. Some forms of regret will surely be illegitimate, as indicated previously. But there are many instances of regretting being infertile (and the feelings and anxiety that go along with it for many women) that are appropriate because they communicate concern for others who will grieve over the infertility, for example, or they prompt one to repair a self that is damaged by sexist and pro-natalist forces. 
Thus, in the context of infertility, regret can be morally good, but self-blame is morally bad, and unfortunately self-blame is common among infertile women. Moreover, the blame represents bad reproductive moral luck for women. As we have shown, women are vulnerable to this luck in societies that define women's function in terms of their capacity for biological reproduction. For women, the elimination of this bad moral luck will require, among other things, that societies replace vibrant or lingering images of women as breeders with other figures of identity. Women must be able to know that they can function well in society without biological children, and that in general, infertility is not a woman's fault.

\section{Acknowledgments}

Funding for this project was provided by the Canadian Institutes of Health Research.

\section{Notes}

${ }^{1}$ The authors contributed equally to this paper.

2 The term "moral luck" is a philosophical term of art, although we use it in a way that is perhaps more broad than how it tends be to used in philosophical work on moral luck. We explain why that is true below.

${ }^{3}$ Less extreme examples are those in which people receive blame for making risky decisions about infertility treatment, decisions that turn out to have been bad ones (perhaps because they leave the woman or couple with no baby and no money). Because the outcomes of these decisions are a matter of luck to some degree, the woman or couple is blamed essentially for 
having bad luck. But we often assume that people ought to be blamed for bad outcomes of their decisions, even though people tend to have limited control over outcomes; hence, the previous type of example is not extreme. By contrast, we tend not to think that people should be blamed for physical conditions, such as infertility; thus, our example of women being blamed for infertility is extreme.

4 "The classic clinical definition of infertility is the absence of conception after twelve months of regular, unprotected intercourse" (Larsen 2005, 846). But many couples conceive without treatment after two years of trying, and in fact, are more likely to conceive in the second year of trying than they are in the first year. Understandably then, the World Health Organization defines infertility as the absence of conception after twenty-four months of regular, unprotected intercourse (Larsen).

${ }^{5}$ We leave out forms of luck that can determine whether one is "cured" of infertility, particularly using assisted reproductive technologies (ARTs). Among these forms are financial luck-the luck that goes with having the ability to afford ARTs, assuming that they are not covered by public health insurance — and geographical and temporal luck—-being at the right place at the right time in terms of being able to access ARTs.

Financial, geographical, and temporal luck also are relevant to whether one can pursue adoption, because adoptions cost money, and restrictions on adoption tend to vary with place and time. For example, many people's temporal luck in being infertile suddenly became bad in 2007 as China implemented new restrictions on who can adopt from China. Among the newly excluded were obese people, people who take medication for anxiety or depression, and people whose net worth is less than $\$ 80,000$ US (Belluck and Yardley 2006). 
${ }^{6}$ For example, a woman who undergoes IVF might end up suffering from ovarian hyperstimulation syndrome, which is a risk of ovarian stimulation. Whether she acquires this syndrome is a matter of biological luck.

${ }^{7}$ Here, we assume that all infertility has a biological component: that is, that the infertility a woman experiences has a physiological cause rooted in either her or her partner or is the product of some biological incompatibility between them. Hence, we exclude from our analysis women whom one might call "infertile" because they are lesbian, for example. We recognize that these women might experience their childlessness as bad moral luck; but in our view, they are not actually infertile and so discussion of their childlessness is beyond the scope of this paper. ${ }^{8}$ Amy Kaler (2007) explains that rumors about causes of infertility are especially pervasive in Africa. In parts of that continent, people assume that one or more of the following leads to sterility: vaccinations (e.g., against polio or smallpox), vitamins, iodized salt, anti-malarial medication, and the list goes on.

${ }^{9}$ By contrast, philosophers working on moral luck tend to assume that the luck makes a moral difference period, not a difference for some groups or some people only.

${ }^{10}$ To be clear, our view is not that all infertile women blame themselves, or that among those who do, the blame is always to the same degree. For example, we assume that women who have come to terms with their infertility are less likely than other women to (actively) blame themselves for it. Unlike women who are struggling to overcome their infertility, these women no longer see their infertility as a serious problem and so are presumably disinclined to blame themselves (or blame anyone else).

${ }^{11}$ For example, Egyptian women face an especially high cultural and religious pressure to conceive. Many Egyptian parents forbid their sons to marry an infertile woman, and Egyptian 
men are still entitled to file for divorce on the grounds of their wives' infertility, although the same entitlement is not extended to women. The stigma of infertility is no less severe for infertile women throughout Africa, who are frequently accused of causing their own infertility. In many African countries, women must still demonstrate fertility before marrying, and infertility is a major cause of divorce and abandonment throughout the continent (Inhorn 1994; Dyer et al. 2002 and 2005).

${ }^{12}$ Much of this research is done on "treatment-seekers" (women who seek out fertility treatment), who may be more likely to blame themselves than other women (see note 8); however, not all of the research is narrow in this way (see, e.g., Abbey and Halman 1995; Vieyra et al. 1990; both cited in Greil 1997).

${ }^{13}$ Many psychological studies on self-blame are problematic in this way (see Shaver and Drown 1986).

14 This belief is tied to an ancient tradition according to which a function implies a capability. Aristotle said that if the function of a knife is to cut, then the knife has the capacity (or the potentiality) to cut. It follows that anything lacking this capacity could not be a knife. Similarly, if a woman's primary function is to bear children, then she must be capable of doing so. Otherwise, she is not truly a woman.

15 This finding — that virility is not terribly important for men in the West - makes sense, given that "being a man" in the West usually involves not procreating, but having lots of nonprocreative sex with different women.

${ }^{16}$ Claudia Card and Lisa Tessman agree that oppressed people can rightfully regret such damage even though they cannot, of course, be blamed for their oppression. 
${ }^{17}$ Margaret Walker describes grace as “acceptance, non-aggrandized daily 'living with' unsupported by fantasies of overcoming or restitution" (Walker 1993, 242). Feeling such acceptance is what it means to come to terms with one's infertility, which is what infertile women need to do if overcoming the infertility (i.e., becoming fertile) is more a fantasy than anything else.

\section{References}

Abbey, A. and L. J. Halman. 1995. The role of perceived control, attributions, and meaning in members' of infertile couples well-being. Journal of social and clinical psychology 14: 271-96.

Aristotle. 1985. Nicomachean ethics. Trans. T. Irwin. Indianapolis: Hackett.

Belluck, Pam and Jim Yardley. 2006. China tightens adoption rules for foreigners. The New York Times, December 20.

Calhoun, Cheshire. 1995. Standing for something. The Journal of Philosophy 92: 235-60.

Card, Claudia. 1996. The unnatural lottery: Character and moral luck. Philadelphia: Temple University Press.

Daniluk, J. C. 2001. 'If we have it to do over again . . '? Couples' reflections on their experiences of infertility treatments. The Family Journal: Counseling and Therapy for Couples and Families 9(2): 122-33.

Dickenson, Donna. 2003. Risk and luck in medical ethics. Cambridge, UK: Polity Press. 
Dyer, S. J., N. Abrahams, M. Hoffman, and Z. M. van der Spuy. 2002. "Men leave me as I cannot have children": Women's experiences with involuntary childlessness. Human Reproduction 17(6): 1663-68.

Dyer, S. J., N. Abrahams, N. E. Mokoena, C. J. Lombard, and Z. M. van der Spuy. 2005. Psychological distress among women suffering from couple infertility in South Africa: A quantitative assessment. Human Reproduction 20 (7): 1938-43.

Guntupalli, A. M., and P. Chenchelgudem. 2004. Perceptions, causes and consequences of infertility among the Chenchu tribe of India. Journal of Reproductive and Infant Psychology 22(4): 249-59.

Greil, Arthur L. 1997. Infertility and psychological distress: A critical review of the literature. Social Science \& Medicine 45(11): 1679-1704.

Homan, G. F., M. Davies, and R. Norman. 2007. The impact of lifestyle factors on reproductive performance in the general population and those undergoing infertility treatment: A review. Human Reproduction Update, January 11 (e-publication ahead of print).

Inhorn, Marcia. 1994. Quest for conception: Gender, infertility, and Egyptian medical traditions. Philadelphia: University of Pennsylvania Press.

Kaler, Amy. 2007. Endangered bodies: Reproductivity, rumours, and counter-epistemic convergence in contemporary Africa. Unpublished manuscript.

Kelly-Weeder, S. and A. O’Connor. 2006. Modifiable risk factors for impaired fertility in women: What nurse practitioners need to know. Journal of the American Academy of Nurse Practitioners 18: 268-76.

Larsen, Ulla. 2005. Research on infertility: Which definition should we use? Fertility and Sterility 83 (4): 846-52. 
Latus, Andrew. 2005. Moral luck. The Internet Encyclopedia of Philosophy. Eds. James Fieser and Bradley Dowden. http://www.iep.utm.edu/m/moralluc.htm

Mackenzie, Catriona. 1992. Abortion and embodiment. Australasian Journal of Philosophy 70 (2): 136-55.

McLeod, Carolyn. 2002. Self-trust and reproductive autonomy. Cambridge, MA: MIT Press.

Nagel, Thomas. 1993. Moral luck. In Statman's Moral luck: 57-71.

Peronace, L. A., J. Boivin, and L. Schmidt. 2007. Patterns of suffering and social interactions in infertile men: 12 months after unsuccessful treatment. Journal of Psychosomatic Obstetrics \& Gynecology 28 (2): 105-114.

Peterson, B. D., C. R. Newton, K. H. Rosen, and G. E. Skaggs. 2006. Gender differences in how men and women who are referred for IVF cope with infertility stress. Human Reproduction, May 4 (e-publication ahead of print).

Schneider, Myra G. and Melinda S. Forthofer. 2005. Associations of psychosocial factors with the stress of infertility treatment. Health \& Social Work 30 (3): 183-91.

Shaver, K. G., and D. Drown. 1986. On causality, responsibility and self-blame: A theoretical note. Journal of Personality and Social Psychology 50 (4): 697-702.

Sherrod, R. A. 2004. Understanding the emotional aspects of infertility: Implications for nursing practice. Journal of Psychosocial Nursing \& Mental Health Services 42 (3): 40-47.

Statman, Daniel, ed. 1993. Moral luck. Albany, State University of New York Press.

Tessman, Lisa. 2005. Burdened virtues: Virtue ethics for liberatory struggles. New York: Oxford University Press. 
Van Rooij, F. B., F. van Balen, and J. M. A. Hermanns. 2007. Emotional distress and infertility: Turkish migrant couples compared to Dutch couples and couples in Western Turkey. Journal of Psychosomatic Obstetrics \& Gynecology 28 (2): 87-95.

Vieyra, M., H. Tennen, G. Affleck, G. Allen, and L. McCann, 1990. The effects of gender and measurement strategy on causal attributions for infertility. Basic and Applied Social Psychology 11: 219-32.

Walker, Margaret Urban. 1993. Moral luck and the virtues of impure agency. In Statman's Moral luck: $235-50$.

Weschler, Toni. 2002. Taking charge of your fertility: The definitive guide to natural birth control, pregnancy achievement, and reproductive health. 2nd ed. New York: HarperCollins. 